\title{
Cancer treatment regimens and their impact on the patient-reported outcome measures health-related quality of life and perceived cognitive function
}

\author{
Niklas Paul Grusdat ${ }^{1 *} \mathbb{D}$, Alexander Stäuber ${ }^{1}$, Marion Tolkmitt ${ }^{2}$, Jens Schnabel ${ }^{2}$, Birgit Schubotz ${ }^{3}$, \\ Peter Richard Wright ${ }^{4}$, Marc Heydenreich ${ }^{5}$, Dirk-Henrik Zermann ${ }^{5}$ and Henry Schulz ${ }^{1}$
}

\begin{abstract}
Background and purpose: Breast cancer can be a significant challenge for those affected. Knowledge of physical function, social-emotional challenges, and perceived cognitive function based on the cancer treatment regimens may help to inform adequate support.

Methods: For this prospective observational pilot study, we collected data of seventy-nine women (mean age $54.6 \pm 9.5$ years) before (T0) and after (T1) initial breast cancer treatment. Functional Assessment of Cancer TherapyBreast (FACT-B) and Functional Assessment of Cancer Therapy-Cognitive-Function (FACT-Cog) were used to collect data of four treatment subgroups: $\mathrm{SCR}=$ Surgery + Chemotherapy + Radiation Therapy; SC = Surgery + Chemotherapy; $S R=$ Surgery + Radiation Therapy; $S=$ Surgery. A mixed ANOVA and posthoc analysis (Tukey, Games-Howell) were used to detect interactions (group by time) and the main effect. A repeated-measures ANOVA displayed individual group differences (time).

Results: Significant interaction showed more deterioration was experienced with SC and SCR than SR and S for FACT$\mathrm{B}(p<0.01)$ and FACT-Cog $(p<0.001)$. The longitudinal comparison between T0 and T1 indicated a significant group main effect on all subscales $(p<0.001)$ except for Emotional Well-Being. Significant reductions $(p<0.05)$ in FACT-B, $(-19 \%)$; FACT-Cog, $(-21 \%)$ with most pronounced effect in Physical Well-Being $(-30 \%)$, Functional Well-Being $(-20 \%)$, Breast Cancer Subscale $(-20 \%)$, Perceived Cognitive Impairments $(-18 \%)$ and Impact of Cognitive Impairments on Quality of Life (-39\%) were detected for SCR.

Conclusion: Our study showed that the extent of change in health-related quality of life (HRQOL) and perceived cognitive function (PCF) depends on the treatment regimen. Multidisciplinary support initiated early in breast cancer therapy is needed, especially for women undergoing combined cancer treatment. Routine assessment of patientreported outcomes (PROs) in oncology practice may increase the transparency of patients' perceived circumstances, leading to personalized and optimized acute and survivorship care.
\end{abstract}

Keywords: HRQoL, Cognitive function, Survivorship, Support

\footnotetext{
*Correspondence: niklas.grusdat@hsw.tu-chemnitz.de

${ }^{1}$ Professorship of Sports Medicine/Sports Biology, Institute of Human Movement Science and Health, Faculty of Behavioral and Social Sciences, Chemnitz University of Technology, Thüringer Weg 11, 09126 Chemnitz, Saxony/Sachsen, Germany

Full list of author information is available at the end of the article
}

\section{Introduction}

Female breast cancer is the most commonly diagnosed cancer worldwide, with an estimated 2.3 million new cases in $2020[1,2]$. About 70,000 new cases are diagnosed in Germany every year [3]. With personalized 
medicine, overall survival has improved in recent decades, especially for patients with early-stage disease [4].

Scientific research has shown evidence of treatmentassociated social-emotional challenges $[5,6]$, physicalfunctional limitations $[7,8]$, and reduced health-related quality of life (HRQoL) [9]. Threats linked to women experiencing breast cancer are chemotherapy-related adverse events, including cognitive impairment such as memory loss, inability to concentrate, difficulty in thinking and processing information [10-12]. Especially at an early stage in life, unmanaged deficits may lead to the inability to function in the workplace or handle instrumental daily living activities, such as finances, shopping, and housekeeping $[13,14]$.

While studies have examined the impact of breast cancer patients receiving active treatment, there are inconsistencies regarding the application of patient reports in routine oncology practice $[15,16]$. Functional Assessment of Cancer Therapy-Breast (FACT-B) and Functional Assessment of Cancer Therapy-Cognitive-Function (FACT-Cog) have gained scientific credibility by providing a comprehensive patient-orientated picture about HRQoL and PCF. Patient-reported outcome (PRO) measures may describe prognostic relevant disease progression, subjective perception of symptoms, the prevalence of satisfaction with care, and the patients' point of view on health status [17-19]. Close monitoring of the patients' situation appears relevant before initiating medical treatment and follow-up to support unmet care needs and conduct a risk stratification.

Alongside the traditional clinical reports, the importance of measuring PRO in patients with breast cancer is required to improve the quality of care [20-22].

Differentiating patient-perceived circumstances regarding treatment regimens (chemotherapy, surgery, radiation therapy, endocrine therapy) may personalize and optimize acute and survivorship care. Further carefully observing treatment-specific conditions may guide the decision-making of a multidisciplinary team of health care specialists. The purpose of the present study was to compare self-reported PROs on HRQoL and PCF in women with breast cancer before and after undergoing various breast cancer treatments.

\section{Methods and ethics}

Between April 2018 and April 2020, a total of 120 patients with the first diagnosis of breast cancer were recruited within the research study "Return" (trial acronym), approved by the Ethics Committee. This study involved humans and addressed health issues. Therefore, it was registered with the German Clinical Trials Register (DRKS). The current study was performed in line with the principles of the Declaration of Helsinki (1986).

\section{Recruitment of patients}

All patients were recruited in a Hospital in ChemnitzRabenstein, Germany. Within one week after a breast cancer diagnosis, patients were invited for consultation by their oncologist and informed about possible participation in the present study. The Return study is part of a series of projects focusing on supporting the participation in survivorship care measures of offered follow-up rehabilitation therapy. Moreover, ambulant oncological exercise therapy groups in survivorship were set up.

Patients were pre-selected and identified as ineligible for participating in this study after checking the medical record and completion of medical history interview with previous invasive malignancy, other malignant tumors, cancer cell metastasis, untreated pulmonary hypertension, diagnosed dementia, and chronic obstructive pulmonary disease. Participants were also excluded due to missing values in the questionnaires, declining consent, or being lost to follow-up. Participants had the opportunity to discuss their participation and read and consider the research information leaflet. A sufficient time ( $>24 \mathrm{~h}$ ) to reflect on the implications of participating in the study was provided. The response rate was $71 \%$. Inclusion criteria for this analysis werepatients' written informed consent, a recent diagnosis of untreated female breast cancer, age $<70$ years. Eighty-five participants who had not initiated cancer treatment met the inclusion criteria and completed the medical interventions. A differentiation into four treatment groups was obtained for statistical analysis of the prospective observational pilot study. Due to ethics and legal considerations, no random assignment occurred. Appointments for the allocated assessments were made immediately and towards the end of medical treatment. Cooperation and coordination between parties involved were required to ensure participation. Further limitations recorded are presented in Fig. 1.

\section{The return study}

According to evidence-based clinical practice guidelines in oncology, every patient could receive the treatment, which was decided by physicians and in line with informed consent and patient agreement. Additionally, this longitudinal study was analyzed by investigators who were not involved in any interventions or clinical decisions to gather information and compare changes over time. Researchers collected data through questionnaires of women with breast cancer to learn more about the effects of different cancer treatments on cognitive health and HRQoL. 


\section{Strobe Flow Diagram}

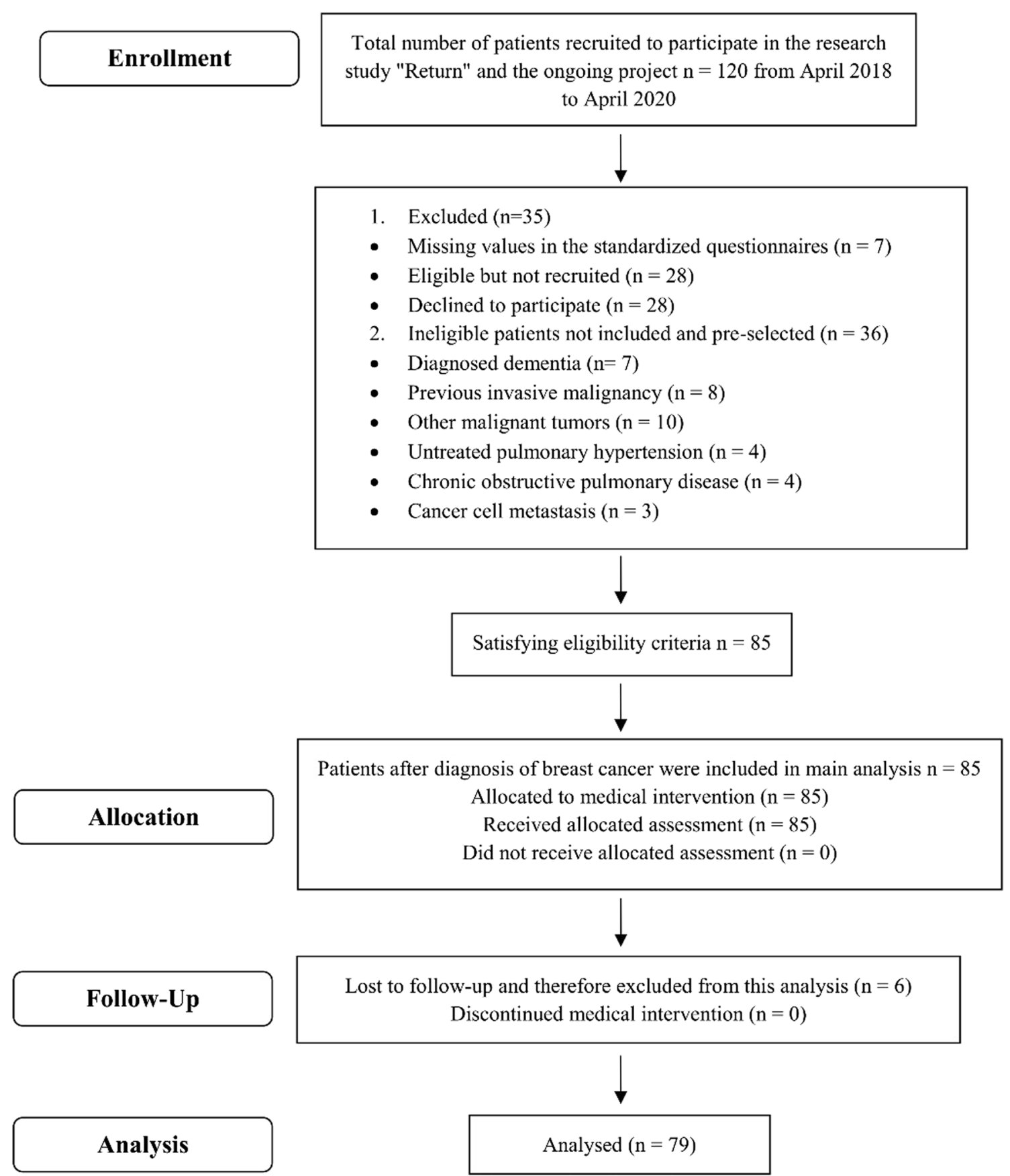

Fig. 1 STROBE flow diagram of the prospective observational pilot study in women with breast cancer

\section{The clinical cancer registry}

With the national German cancer registry law, nationwide epidemiological cancer registries were established in 1995. Consequentially, the German National Cancer Plan worked out a legal basis for national clinical cancer registries (CCR). Existing structures were expanded to clinical and epidemiological CRs. A joint evaluation point, a central coordination point, a common Tumor database, and a scientific advisory board were installed.

Physicians and hospitals (service providers) have the statutory duty to notify clinical markers related to cancer, such as tumor localization, tumor pathology, 
estrogen receptor, progesterone receptor, human epidermal growth factor receptor status, parameters for tumor grading, UICC status, and medical interventions. The optimization of linked datasets offers opportunities for research studies due to access to patient information. All in all, CCRs have the realistic potential to improve oncological health care throughout Germany [3, 23]. Further, joint activities of all health policies and scientific actors involved in the fight against cancer are indispensable to continue withstanding the high pressure to innovate, primarily by targeted oncological drugs.

\section{Measurements}

All assessments were carried out before (T0) and within one week after completing (T1) conventional cancer treatment (surgery, chemotherapy, radiation therapy). Cases with long-term endocrine therapy continued beyond T1. Based on the variable duration of breast cancer treatment for each woman, repeated testing ( $\mathrm{T} 0$ and T1) was performed at different time intervals. Four treatment subgroups were included for the following analysis (SC, Surgery + Chemotherapy; SCR, Surgery + Chemotherapy+Radiation Therapy; SR, Surgery+Radiation Therapy; S, Surgery). Height and weight were measured with footwear and headwear removed using a standard stadiometer and weigh scale, Seca IEC 601 (Vogel \& Halke, Hamburg, Germany). These parameters allowed the calculation of the body mass index (BMI) by using the formula $B M I=\frac{w e i g h t(\mathrm{~kg})}{\operatorname{height}(\mathrm{m})^{2}}$.

\section{The questionnaires}

Eligible patients were asked to fill out the validated German translations of the Functional Assessment of Cancer Therapy-Breast (FACT-B) and the Functional Assessment of Cancer Therapy-Cognitive Function (FACT-Cog) questionnaires. All patients completed the questionnaires with qualified personnel available to answer any questions or clarify any meaning. For FACT-B and FACT-Cog, higher scores (negative items were reversescored) indicate a subjectively better HRQoL or PCF. The past seven days as the recall period are covered by both questionnaires, which includes times when patients were undergoing treatment. The FACT-B (version 4) instrument has a score range of $0-148$ points and consists of 37 questions and item codes. It is designed to capture five domains in breast cancer patients: Physical Well-Being (PWB 0 to 28), Social/Family Well-Being (SWB 0 to 28), Emotional Well-Being (EWB 0-24), Functional WellBeing (FWB 0-28), and Breast Cancer Subscale (BCS $0-40)$. For each question of the subscales, a response is required on a 5 -point Likert-type scale ( 0 , not at all; 1 , a little bit; 2 some-what; 3 , quite a bit; 4 , very much) (see Table 1) [17, 24].
The FACT-Cog version 3 consists of 33 questions and item codes to derive a total score (0 to 132). It has four subscales representing PCF and its impact on quality of life: Perceived Cognitive Impairments (PCI 0-72), Comments From Others (OTH 0-16), Perceived Cognitive Abilities (PCA, 0-28), and Impact of Perceived Cognitive Function on Quality of Life (QoL 0-16). The Likert-type scales offer the option to identify patients' perceived situation regarding frequency and intensity: $\mathrm{PCI}, \mathrm{OTH}=0$, Never; 1, About once a week; 2, Two to three times a week; 3 , Nearly every day; 4 , Several times a day; and PCA, QoL $=0$, not at all; 1, a little bit; 2, some-what; 3, quite a bit; 4 , very much (see Table 2).

Negatively worded items of the subscales (e.g., "I have had trouble forming thoughts") were reversed in the calculation for the final score. The scoring key for all items is reversed except for the PCA subscale. Two items of PCA and PCI were not scored because these items, related to multitasking, have not yet been validated and incorporated with the current FACT-Cog scoring algorithm [18, 25].

\section{Statistical analysis/data analysis}

The data analysis was performed with the statistical software package IBM SPSS statistics 26 (Chicago, IL, USA). Only those patients who completed all assessments were included in the analysis. Descriptive statistics are presented as mean, standard deviation (SD), and the minimum and maximum of the outcome parameters. A significance level of $\mathrm{P}<0.05$ for data analyses was set. Demographic characteristics (age, height, weight, BMI) were tested using ANOVA to ensure comparability between the study groups. All metric data were normally distributed (Shapiro-Wilk test) $p>0.05$, and the null hypothesis was not rejected (shown in Table 3). For applying mixed (between-within) ANOVA, sphericity was identified (Mauchly test). Variances of the four study groups were equal (homogeneity) (Levene's test). Univariate ANOVA with intermediate subject effects demonstrated no significant group differences on the dependent variables at T0 $(p>0.05)$. The main effects for time (whole group), the interaction between time and group (difference between groups), as well as group comparison regardless of the time, were tested for significant effects using a mixed ANOVA and posthoc analysis (Tukey, Games-Howell). Group differences over time were investigated with main effects of the betweensubjects factor and secondary outcome variables with a repeated measure analysis of variance for main effects of the within-subject factor (Greenhouse-Geisser). F indicates that the test procedure uses an F statistic based on the $\mathrm{F}$ distribution. 
Table 1 Functional Assessment of Cancer Therapy-Breast (FACT-B, version 4)

\begin{tabular}{|c|c|c|c|}
\hline \multirow[t]{2}{*}{ Subscale } & \multicolumn{3}{|c|}{ FACT-B (version 4) } \\
\hline & Item ID & Item/question & Response options \\
\hline \multirow[t]{7}{*}{ PWB } & GP1 & I have a lack of energy & Intensity (not at all, a little bit, somewhat quite a bit, very much) \\
\hline & GP2 & I have nausea & \\
\hline & GP3 & $\begin{array}{l}\text { Because of my physical condition, I have trouble meeting the } \\
\text { needs of my family }\end{array}$ & \\
\hline & GP4 & I have pain & \\
\hline & GP5 & I am bothered by side effects of treatment & \\
\hline & GP6 & I feel ill & \\
\hline & GP7 & I am forced to spend time in bed & \\
\hline \multirow[t]{7}{*}{ SWB } & GS1 & I feel close to my friends & Intensity (not at all, a little bit, somewhat quite a bit, very much) \\
\hline & GS2 & I get emotional support from my family & \\
\hline & GS3 & I get support from my friends & \\
\hline & GS4 & My family has accepted my illness & \\
\hline & GS5 & I am satisfied with family communication about my illness & \\
\hline & GS6 & $\begin{array}{l}\text { I feel close to my partner (or the person who is my main sup- } \\
\text { port) }\end{array}$ & \\
\hline & GS7 & I am satisfied with my sex life & \\
\hline \multirow[t]{6}{*}{ EWB } & GE1 & I feel sad & Intensity (not at all, a little bit, somewhat quite a bit, very much) \\
\hline & GE2 & I am satisfied with how I am coping with my illness & \\
\hline & GE3 & I am losing hope in the fight against my illness & \\
\hline & GE4 & I feel nervous & \\
\hline & GE5 & I worry about dying & \\
\hline & GE6 & I worry that my condition will get worse & \\
\hline \multirow[t]{7}{*}{ FWB } & GF1 & I am able to work (include work at home) & Intensity (not at all, a little bit, somewhat quite a bit, very much) \\
\hline & GF2 & My work (include work at home) is fulfilling & \\
\hline & GF3 & I am able to enjoy life & \\
\hline & GF4 & I have accepted my illness & \\
\hline & GF5 & I am sleeping well & \\
\hline & GF6 & I am enjoying the things I usually do for fun & \\
\hline & GF7 & I am content with the quality of my life right now & \\
\hline \multirow[t]{10}{*}{$\mathrm{BCS}$} & B1 & I have been short of breath & Intensity (not at all, a little bit, somewhat quite a bit, very much) \\
\hline & B2 & I am self-conscious about the way I dress & \\
\hline & B3 & One or both of my arms are swollen or tender & \\
\hline & B4 & I feel sexually attractive & \\
\hline & B5 & I am bothered by hair loss & \\
\hline & B6 & $\begin{array}{l}\text { I worry that other members of my family might someday get } \\
\text { the same illness I have }\end{array}$ & \\
\hline & B7 & I worry about the effect of stress on my illness & \\
\hline & B8 & I am bothered by a change in weight & \\
\hline & B9 & I am able to feel like a woman & \\
\hline & P2 & I have certain parts of my body where I experience pain & \\
\hline
\end{tabular}

Additionally, we performed the repeated-measures ANOVA for each group separately to inspect if the individual groups differed significantly $(p<0.05)$ between T0 and T1 (Greenhouse-Geisser). Significant interaction effects were reviewed with post hoc test Tukey-HSD for multiple comparisons, which allowed identification of groups differing from each at $\mathrm{T} 0$ and $\mathrm{T} 1$.
The effect size was calculated by using the formula: partialn ${ }^{2}=\frac{S S_{\text {effect }}}{\text { SSeffect+SSerror }}$. Suggested benchmarks for interpretation of the effect size are small $(0.1-0.3)$, medium (0.3-0.5) and large (>0.5) [26]. Cronbachs alpha formula: $a=\frac{N \bar{c}}{\bar{v}+(N-1) \bar{c}}$ provided reliability of used questionnaires on the sample in this research. The 
Table 2 Functional Assessment of Cancer Therapy-Cognitive Function (FACT-Cog, Version 3)

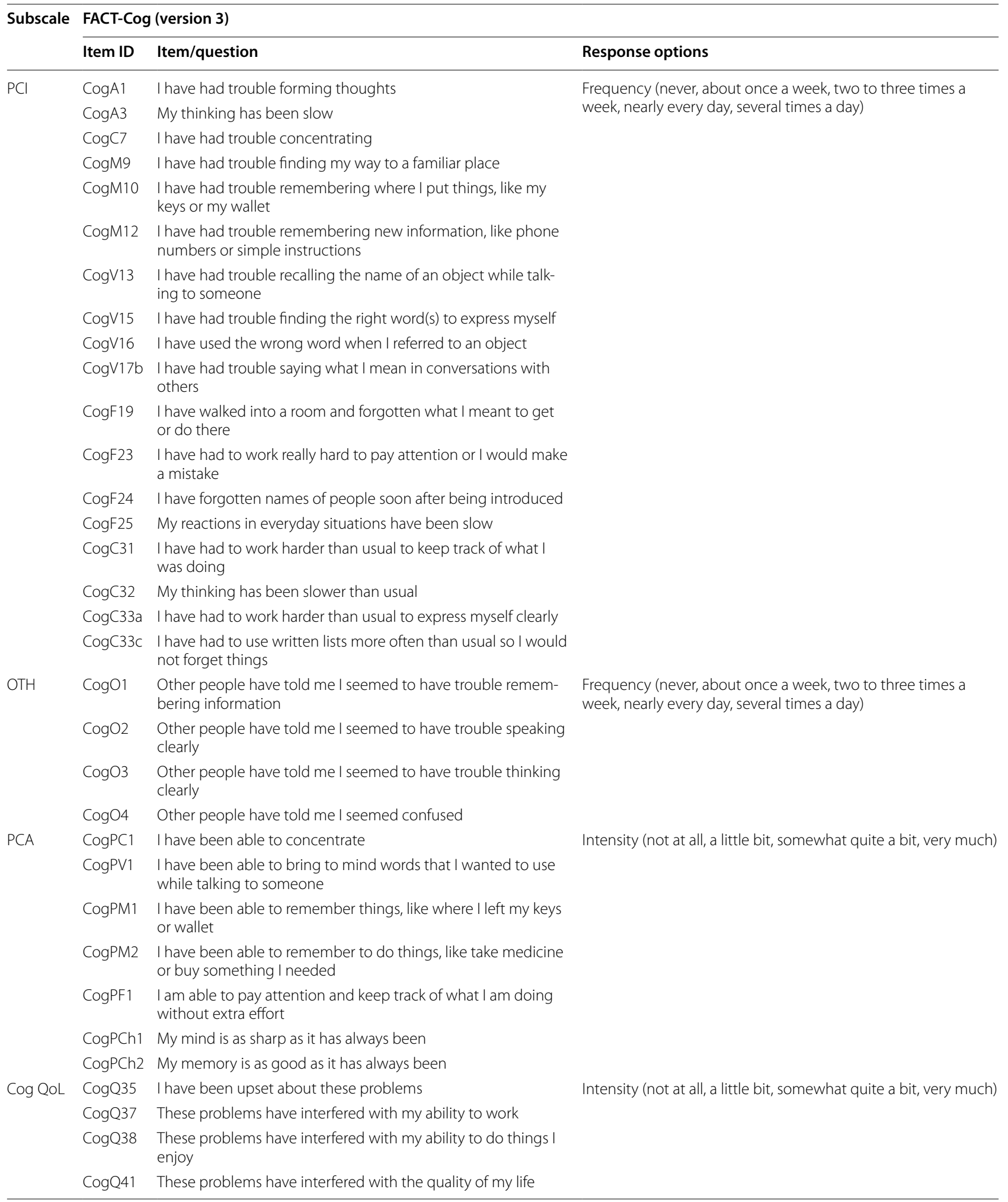


Table 3 Baseline demographics and patients' clinical characteristics of $n=79$ women with breast cancer

\begin{tabular}{|c|c|c|c|c|}
\hline Variable & Group SC & Group SCR & Group SR & Group S \\
\hline N. (\%) & $22(100.0)$ & $17(100.0)$ & $27(100.0)$ & $13(100.0)$ \\
\hline Age [years] & $51.9 \pm 11.6$ & $54.4 \pm 8.5$ & $56.7 \pm 9.0$ & $55.3 \pm 7.3$ \\
\hline$p$ & 0.30 & 0.21 & 0.06 & 0.28 \\
\hline Age, $30-35$ years $n(\%)$ & $2(9.1)$ & $0(0.0)$ & $0(0.0)$ & $0(0.0)$ \\
\hline Age, $35-40$ years $n(\%)$ & $2(9.1)$ & $0(0.0)$ & $3(11.1)$ & $0(0.0)$ \\
\hline Age, $41-49$ years $n(\%)$ & $5(22.7)$ & $6(45.5)$ & $2(7.4)$ & $3(23.1)$ \\
\hline Age, $50-59$ years $n(\%)$ & $6(27.3)$ & $4(23.5)$ & $9(33.3)$ & $6(46.2)$ \\
\hline Age, 60-69 years $n(\%)$ & $7(31.8)$ & $7(41.2)$ & $13(48.2)$ & $4(30.8)$ \\
\hline Height [m] & $1.65 \pm 0.08$ & $1.65 \pm 0.08$ & $1.61 \pm 0.06$ & $1.63 \pm 0.08$ \\
\hline$p$ & 0.43 & 0.77 & 0.56 & 0.24 \\
\hline Weight [kg] & $72.1 \pm 14.2$ & $82.7 \pm 20.2$ & $68.6 \pm 12.4$ & $72.6 \pm 12.5$ \\
\hline$p$ & 0.29 & 0.11 & 0.66 & 0.55 \\
\hline BMI $\left[\mathrm{kg} \mathrm{m}^{-2}\right]$ & $26.4 \pm 5.0$ & $30.5 \pm 6.8$ & $26.4 \pm 4.8$ & $27.4 \pm 4.3$ \\
\hline$p$ & 0.08 & 0.08 & 0.48 & 0.17 \\
\hline UICC n (\%) & $\begin{array}{l}\text { IA: } 5(22.7) \\
\text { IIA:10 (45.5) IIA: } 1 \text { (4.6) } \\
\text { IIB: } 6(27.3)\end{array}$ & $\begin{array}{l}\text { IA: } 7(41.2) \\
\text { II:7 (41.2) } \\
\text { IB: } 2(11.8) \\
\text { IIB: } 1(5.9)\end{array}$ & $\begin{array}{l}\text { IA: } 25(92.6) \\
\| A: 2(7.4) \\
\text { IB: } 0(0.0) \\
\text { IIB: } 0(0.0)\end{array}$ & $\begin{array}{l}\text { IA: } 5(38.5) \\
\text { IIA: } 8(61.5) \\
\text { IB: } 0(0.0) \\
\| B: 0(0.0)\end{array}$ \\
\hline $\mathrm{TT}$ (month) & $7.7 \pm 1.3$ & $10.4 \pm 1.6$ & $5.3 \pm 1.5$ & $2.5 \pm 1.6$ \\
\hline $\begin{array}{l}\text { Her2/neu status, } \\
\text { n(\%) }\end{array}$ & $\begin{array}{l}\text { Pos. } 1 \text { (4.5) } \\
\text { Neg. } 21 \text { (94.5) }\end{array}$ & $\begin{array}{l}\text { Pos. } 2 \text { (11.8) } \\
\text { Neg. } 15 \text { (88.2) }\end{array}$ & $\begin{array}{l}\text { Pos. } 0 \text { (0.0) } \\
\text { Neg. } 27 \text { (100.0) }\end{array}$ & $\begin{array}{l}\text { Pos. } 13(100.0) \\
\text { Neg. } 0(0.0)\end{array}$ \\
\hline $\begin{array}{l}\text { ER status, } \\
\text { n (\%) }\end{array}$ & $\begin{array}{l}\text { Pos. } 13 \text { (59.1) } \\
\text { Neg. } 9 \text { (40.9) }\end{array}$ & $\begin{array}{l}\text { Pos. } 14 \text { (82.4) } \\
\text { Neg. } 3(17.7)\end{array}$ & $\begin{array}{l}\text { Pos. } 27(100.0) \\
\text { Neg. } 0(0.0)\end{array}$ & $\begin{array}{l}\text { Pos. } 13(100.0) \\
\text { Neg. } 0(0.0)\end{array}$ \\
\hline$M C, n(\%)$ & $1(4.6)$ & $1(5.9)$ & $0(0.0)$ & $0(0.0)$ \\
\hline IDC, n (\%) & 18 (81.8) & $16(94.1)$ & $24(88.9)$ & $7(53.9)$ \\
\hline IDC-L, n (\%) & $0(0.0)$ & $0(0.0)$ & $0(0.0)$ & $1(7.7)$ \\
\hline ILC, n (\%) & $3(13.6)$ & $0(0.0)$ & $2(7.4)$ & $5(38.5)$ \\
\hline ICC, n (\%) & $0(0.0)$ & $0(0.0)$ & $1(3.7)$ & $0(0.0)$ \\
\hline SNB, n (\%) & $21(95.5)$ & $15(88.2)$ & $27(100.0)$ & $13(100.0)$ \\
\hline ALND, n (\%) & $5(22.7)$ & $3(17.7)$ & $0(0.0)$ & $0(0.0)$ \\
\hline BCS, n (\%) & $8(36.4)$ & $16(94.1)$ & $27(100.0)$ & $0(0.0)$ \\
\hline MRM, n (\%) & $2(9.1)$ & $1(5.9)$ & $0(0.0)$ & $2(15.4)$ \\
\hline SCM, n (\%) & $9(40.9)$ & $0(0.0)$ & $0(0.0)$ & $10(76.9)$ \\
\hline $\mathrm{BCS}+\mathrm{SCM}, \mathrm{n}(\%)$ & $3(13.6)$ & $0(0.0)$ & $0(0.0)$ & $1(7.7)$ \\
\hline TMX, n (\%) & $1(4.5)$ & $4(23.5)$ & $6(22.2)$ & $1(7.7)$ \\
\hline ALs, n (\%) & $13(59.1)$ & $9(52.9)$ & $20(74.1)$ & $11(84.6)$ \\
\hline Neoadjuvant C, n (\%) & $10(45.5)$ & $9(52.9)$ & $0(0.0)$ & $0(0.0)$ \\
\hline Adjuvant C, n (\%) & $13(59.1)$ & $8(47.1)$ & $0(0.0)$ & $0(0.0)$ \\
\hline Anth-bCTx, n (\%) & $12(54.6)$ & $9(52.9)$ & $0(0.0)$ & $0(0.0)$ \\
\hline TaxAnth-C, n (\%) & $10(45.5)$ & $8(47.1)$ & $0(0.0)$ & $0(0.0)$ \\
\hline R, n (\%) & $0(0.0)$ & $17(100.0)$ & $27(100.0)$ & $0(0.0)$ \\
\hline
\end{tabular}

Means \pm standard deviation (SD); $\mathrm{n}=$ number of patients (\%); normally distribution (Shapiro-Wilk test) $p>0.05$; SCR, Surgery + Chemotherapy + Radiotherapy; SC; SR; S; ALND, Axillary lymph node dissection; ALs, Aromatase inhibitors; Anth-bC, Anthracycline-Based Chemotherapy; BCS, Breast-conserving surgery; ER, estrogen receptor; HER2/neu, human epidermal growth factor receptor 2; ICC, invasive cribriform carcinoma; IDC, Invasive ductal carcinoma; IDC-L, invasive ductal carcinoma with lobular features; ILC, invasive lobular carcinoma; MC, Mucinous breast carcinoma; MRM, Modified Radical Mastectomy; R, Radiotherapy; SCM, Subcutaneous mastectomy; SNB, Sentinel node biopsy; TMX, Tamoxifen; TaxAnth-C, Anthracycline-Taxane-Based Chemotherapy; TT, Time of Treatment; UICC, Union for International Cancer Control 
measured internal consistency for FACT B (0.76) and for FACT-COG (0.84) was good to very good [27].

\section{Results}

The Federal Clinical Cancer Registry provided patients' clinical characteristics through a comprehensive registration of tumor cases. Along with the assessed baseline demographics, data were displayed in Table 3.

Seventy-nine women $(100 \%)$ with breast cancer were included in the present analysis. The mean (SD) age of the total sample at diagnosis was $54.6 \pm 9.5$ years (range $=30$ to 69 years). The mean (SD) time interval between diagnosis of breast cancer and initial data collection before starting treatment for breast cancer (T0) was $6.8 \pm 1.3$ days (range 5.0-9.0 days). The written informed consent for participation in this study after diagnosis was given within $4.5 \pm 1.2$ days (range 2.0-7.0 days). All women with primary disease completed their cycles of chemotherapy, treatment sessions of radiation therapy, or cancer surgery. The mean (SD) time for completing therapy was 6.6 \pm 3.0 months (range 1.0-13.4 months.). After breast cancer treatment, follow-up data were collected within one week (mean $5.7 \pm 0.8$ days, range 4.0 - 7.0 days). The length of treatment (TT) or treatment period was defined as the time from the day of diagnosis, including treatment initiation and the disappearance of all signs of cancer in response to treatment certified by the individual's treating health care professional. Completing breast treatment does not always mean that cancer has been cured. A treatment period lasting more than twelve months requires a review of the need for continued treatment.

\section{Health-related quality of life}

The longitudinal comparison indicated a significant main (time) effect on the FACT-B and all subscales except EWB, with medium to large effect size in FACT$\mathrm{B}$ and BCS presented in Table 4. Regarding group allocation (individual group), T0 to T1 differences were not significant for all four groups $(p>0.05)$ on SWB, EWB, and FWB. The highest on average score change for each patient (percentage) was detected in SCR (PWB - 30\%, BCS $-20 \%$, SWB $-15 \%$, FWB $-20 \%$ FACT-B $-19 \%$ ) compared to S (PWB - 12\%, BCS - 7\%, SWB - 9\%, FWB $-5 \%$, FACT-B $-7 \%$ ). All groups showed a more than $10 \%$ reduction in PWB. More than a $10 \%$ reduction was detected in FWB in SC, SCR, and SR. Significant groupby-time interaction for FACT-B, FWB, BCS showed more deterioration experienced with $\mathrm{SC}$ and SCR than $\mathrm{SR}$ and $\mathrm{S}$. The effect size for the primary outcome variable was small.

All groups' mean EWB $(15.5 \pm 3.9)$ represented around $65 \%$ of the total item score (maximum achievable amount of points; 24 points) at T0. FACT-B mean score of the overall group at T0 $(114.0 \pm 13.0)$ reached $73 \%$ of the maximum score (148 points) and $64 \%$ at T1 (FACT-B $100.2 \pm 16.6)$. The overall group means for EWB and FACT-B do not report the average score change for each patient in time.

\section{Perceived cognitive function}

Significant main effect (time) was shown in FACT-Cog; PCI; OTH; PCA; QoL, with large effects sizes in FACT$\mathrm{Cog}$ and PCI. Individual groups (S, SR), T0 to T1 differences were not significant for all subscales $(p>0.05)$. Moreover, there was no significant effect detected in the time of $\mathrm{S}$. The highest on average score change for each patient (percentage) was established for SCR (PCI $-18 \%$, OTH $-15 \%$, PCA $-18 \%$, QoL $-39 \%$ FACT-Cog $-21 \%)$ compared to $\mathrm{S}(\mathrm{PCI}-2 \%$, OTH $-2 \%$, PCA $-2 \%$, QoL $+2 \%$ FACT-Cog $-1 \%)$.

A significant group $\times$ time interaction for FACT-Cog; PCI; OTH; PCA; QoL was detected as SC and SCR presented more reductions than SR, and S. Testing partial $\mathrm{n}^{2}$ showed a medium to large effect size for FACT-Cog, PCI, OTH, PCA, and QoL. The results of the primary outcome measure, the FACT-B, and the FACT-Cog, are presented in Table 4.

FACT-Cog mean score of the entire group $(117.3 \pm 14.6)$ at $\mathrm{T} 0$ reached $89 \%$ of maximum score (maximum achievable amount of points; 132 ) and $80 \%$ at T1 (FACT-Cog 104.9 \pm 14.7).

\section{Discussion}

Based on the preliminary data of the research study "Return", we analyzed the PRO measures HRQoL and PCF in women with breast cancer regarding their cancer treatments. Monitoring with the help of clinically established assessment procedures was conducted. Our main findings provide evidence of decreased HRQoL and PCF across all groups, with the most pronounced impact in SCR following multi-modular treatment. Differences were shown in the reduced FWB, BCS, PCI, $\mathrm{PCA}, \mathrm{OTH}$, and Cog QoL of women receiving additional chemotherapy.

The significantly reduced HRQoL and PCF of women in the presented study might reflect an increased demand for supportive care to compensate for the side effects of breast cancer treatment and throughout the different stages of therapy. The oncological care pathway in Germany includes acute medical treatment and voluntary follow-up rehabilitation in the clinical setting of three weeks immediately or at the latest three weeks after discharge of hospital treatment [28, 29].

Early post-diagnostic regular exercise with moderate-to-vigorous intensity may prevent unfavorable 
Table 4 The primary outcome measures of the FACT-B and the FACT-Cog in the treatment subgroups

\begin{tabular}{|c|c|c|c|c|c|c|c|c|c|c|c|}
\hline \multirow[t]{2}{*}{ Variable } & \multirow[t]{2}{*}{ G } & \multicolumn{2}{|l|}{ Mean (SD) } & \multirow[t]{2}{*}{$n$} & \multirow{2}{*}{$\begin{array}{l}\text { Change } \\
\text { (\%) }\end{array}$} & \multirow[t]{2}{*}{ IG T* } & \multirow[t]{2}{*}{ F-T } & \multirow[t]{2}{*}{$F-G$} & \multirow[t]{2}{*}{ F-GxT } & \multirow{2}{*}{$\begin{array}{l}\eta^{2} \\
(T)\end{array}$} & \multirow{2}{*}{$\begin{array}{l}\eta^{2} \\
(G \times T)\end{array}$} \\
\hline & & T0 & $\mathrm{T} 1$ & & & & & & & & \\
\hline \multirow{4}{*}{$\begin{array}{l}\text { FACT-B } \\
(0-148)\end{array}$} & SC & $114.5 \pm 13.9$ & $98.8 \pm 14.7$ & 22 & $-13.2 \pm 11.9$ & a & \multirow[t]{4}{*}{$82.62^{* * *}$} & \multirow[t]{4}{*}{$0.17^{\mathrm{NS}}$} & \multirow[t]{4}{*}{$4.12^{* *}$} & \multirow[t]{4}{*}{0.52} & \multirow[t]{4}{*}{0.14} \\
\hline & $S C R$ & $116.7 \pm 12.1$ & $94.8 \pm 18.9$ & 17 & $-18.6 \pm 13.8$ & a & & & & & \\
\hline & $S R$ & $113.5 \pm 16.9$ & $103.8 \pm 19.2$ & 27 & $-8.8 \pm 8.6$ & a & & & & & \\
\hline & S & $111.4 \pm 9.1$ & $103.5 \pm 13.4$ & 13 & $-7.3 \pm 7.5$ & a & & & & & \\
\hline \multirow{4}{*}{$\begin{array}{l}\text { PWB } \\
(0-28)\end{array}$} & SC & $24.7 \pm 2.1$ & $19.8 \pm 4.9$ & 22 & $-19.5 \pm 20.5$ & a & \multirow[t]{4}{*}{$70.47^{* * *}$} & \multirow[t]{4}{*}{$1.35^{\mathrm{NS}}$} & $2.26^{\mathrm{NS}}$ & 0.48 & 0.08 \\
\hline & $S C R$ & $23.9 \pm 2.9$ & $16.8 \pm 6.3$ & 17 & $-29.7 \pm 23.4$ & a & & & & & \\
\hline & $S R$ & $24.0 \pm 3.8$ & $20.0 \pm 5.2$ & 27 & $-16.7 \pm 17.0$ & a & & & & & \\
\hline & S & $24.1 \pm 2.8$ & $21.3 \pm 4.1$ & 13 & $-11.5 \pm 12.9$ & a & & & & & \\
\hline SWB & SC & $23.0 \pm 3.4$ & $20.2 \pm 3.4$ & 22 & $-11.5 \pm 14.4$ & a & $36.35^{* * *}$ & $0.86^{\mathrm{NS}}$ & $2.60^{\mathrm{NS}}$ & 0.33 & 0.09 \\
\hline & $S C R$ & $24.8 \pm 3.0$ & $21.0 \pm 3.9$ & 17 & $-15.3 \pm 10.8$ & a & & & & & \\
\hline & $S R$ & $22.4 \pm 3.9$ & $21.3 \pm 5.0$ & 27 & $-4.2 \pm 20.1$ & & & & & & \\
\hline & S & $21.8 \pm 3.5$ & $19.9 \pm 5.0$ & 13 & $-9.1 \pm 17.2$ & & & & & & \\
\hline EWB & SC & $15.2 \pm 4.8$ & $15.7 \pm 3.9$ & 22 & $+7.7 \pm 29.9$ & & $0.47^{\mathrm{NS}}$ & $0.09^{\mathrm{NS}}$ & $0.16^{\mathrm{NS}}$ & 0 & 0 \\
\hline$(0-24)$ & $S C R$ & $15.8 \pm 3.1$ & $15.7 \pm 3.5$ & 17 & $+0.7 \pm 20.1$ & & & & & & \\
\hline & $S R$ & $15.1 \pm 4.6$ & $15.5 \pm 4.9$ & 27 & $+3.4 \pm 22.2$ & & & & & & \\
\hline & S & $15.9 \pm 2.9$ & $16.0 \pm 2.5$ & 13 & $+1.3 \pm 8.2$ & & & & & & \\
\hline FWB & SC & $19.4 \pm 6.5$ & $15.7 \pm 5.4$ & 22 & $-16.7 \pm 15.5$ & a & $51.36^{* * *}$ & $0.33^{\mathrm{NS}}$ & $3.25^{*}$ & 0.41 & 0.12 \\
\hline$(0-28)$ & $S C R$ & $20.9 \pm 5.2$ & $16.1 \pm 4.3$ & 17 & $-19.8 \pm 20.5$ & a & & & & & \\
\hline & $S R$ & $20.0 \pm 4.7$ & $17.7 \pm 4.4$ & 27 & $-10.3 \pm 11.9$ & a & & & & & \\
\hline & S & $18.8 \pm 3.8$ & $17.5 \pm 3.3$ & 13 & $-5.4 \pm 12.5$ & & & & & & \\
\hline BCS & SC & $32.0 \pm 3.5$ & $27.5 \pm 4.8$ & 22 & $-14.1 \pm 12.3$ & a & $76.11^{* * *}$ & $1.03^{\mathrm{NS}}$ & $3.98^{*}$ & 0.5 & 0.13 \\
\hline$(0-40)$ & $S C R$ & $31.4 \pm 4.4$ & $25.2 \pm 6.3$ & 17 & $-19.7 \pm 14.8$ & a & & & & & \\
\hline & $S R$ & $32.0 \pm 4.1$ & $29.3 \pm 5.5$ & 27 & $-9.1 \pm 10.7$ & a & & & & & \\
\hline & S & $30.8 \pm 4.1$ & $28.7 \pm 5.0$ & 13 & $-6.8 \pm 10.6$ & a & & & & & \\
\hline FACT- & SC & $118.1 \pm 13.4$ & $100.4 \pm 11.8$ & 22 & $-14.9 \pm 6.0$ & a & $168.53^{* * *}$ & $1.64^{\mathrm{NS}}$ & $27.93^{* * *}$ & 0.69 & 0.53 \\
\hline $\operatorname{Cog}$ & $S C R$ & $117.9 \pm 11.8$ & $93.6 \pm 13.8$ & 17 & $-20.5 \pm 9.4$ & a & & & & & \\
\hline (0-132) & $S R$ & $116.3 \pm 14.5$ & $110.9 \pm 18.4$ & 27 & $-5.1 \pm 6.6$ & a & & & & & \\
\hline & S & $116.9 \pm 18.6$ & $114.5 \pm 14.9$ & 13 & $-1.3 \pm 6.5$ & & & & & & \\
\hline $\mathrm{PCl}$ & SC & $64.2 \pm 10.0$ & $56.7 \pm 9.1$ & 22 & $-11.6 \pm 5.0$ & a & $118.70^{* * *}$ & $1.09^{\mathrm{NS}}$ & $15.07^{* * *}$ & 0.61 & 0.38 \\
\hline$(0-72)$ & $S C R$ & $64.8 \pm 7.4$ & $52.9 \pm 9.2$ & 17 & $-18.1 \pm 11.6$ & a & & & & & \\
\hline & $S R$ & $64.5 \pm 7.7$ & $61.1 \pm 9.8$ & 27 & $-5.6 \pm 7.1$ & a & & & & & \\
\hline & S & $64.5 \pm 10.0$ & $62.8 \pm 8.3$ & 13 & $-2.2 \pm 7.1$ & & & & & & \\
\hline OTH & SC & $15.5 \pm 1.0$ & $13.7 \pm 2.0$ & 22 & $-11.9 \pm 11.7$ & a & $55.83^{* * *}$ & $1.14^{\mathrm{NS}}$ & $10.82^{* * *}$ & 0.43 & 0.3 \\
\hline$(0-$ & $S C R$ & $15.4 \pm 1.5$ & $13.1 \pm 1.7$ & 17 & $-15.0 \pm 9.5$ & a & & & & & \\
\hline & $S R$ & $15.6 \pm 0.8$ & $15.2 \pm 0.9$ & 27 & $-2.0 \pm 5.7$ & & & & & & \\
\hline & S & $15.7 \pm 0.6$ & $15.4 \pm 1.0$ & 13 & $-1.9 \pm 5.1$ & & & & & & \\
\hline PCA & SC & $25.1 \pm 3.2$ & $20.6 \pm 3.2$ & 22 & $-17.2 \pm 11.4$ & a & $91.45^{* * *}$ & $0.76^{\mathrm{NS}}$ & $17.40^{* * *}$ & 0.55 & 0.41 \\
\hline$(0-28)$ & $S C R$ & $24.1 \pm 3.2$ & $19.6 \pm 3.0$ & 17 & $-18.4 \pm 7.8$ & a & & & & & \\
\hline & $S R$ & $23.4 \pm 4.8$ & $22.6 \pm 5.1$ & 27 & $-3.6 \pm 8.3$ & a & & & & & \\
\hline & S & $24.2 \pm 4.5$ & $23.7 \pm 4.0$ & 13 & $-1.7 \pm 6.7$ & & & & & & \\
\hline QoL & SC & $13.3 \pm 2.8$ & $9.3 \pm 1.9$ & 22 & $-28.2 \pm 14.0$ & a & $85.35^{* * *}$ & $1.44^{\mathrm{NS}}$ & $22.49^{* * *}$ & 0.53 & 0.47 \\
\hline$(0-16)$ & $S C R$ & $13.6 \pm 2.6$ & $8.0 \pm 1.9$ & 17 & $-39.2 \pm 17.1$ & a & & & & & \\
\hline & $S R$ & $12.8 \pm 3.4$ & $11.9 \pm 4.2$ & 27 & $-8.2 \pm 20.1$ & & & & & & \\
\hline & S & $12.5 \pm 4.6$ & $12.7 \pm 3.0$ & 13 & $+1.8 \pm 14.6$ & & & & & & \\
\hline
\end{tabular}

Data are expressed as means \pm standard deviation (SD); Change in percent (\%) represent the average score change of each patient For FACT-B and FACT-Cog, higher scores indicate a subjectively better HRQoL or PCF

SC, Surgery + Chemotherapy; SCR, Surgery + Chemotherapy + Radiation Therapy; SR, Surgery + Radiation Therapy; S, Surgery; n, number of patients; NS, not significant; $T$, time; $G$, group; $F-T$, main effect for time group; $F-G$, main effect for group regardless of the time; $G \times T$, interaction between time and group; IG T, individual group for time 
Table 4 (continued)

${ }^{*} p<0.05 ;{ }^{* *} p<0.01 ;{ }^{* * *} p<0.001$

"a" expresses statistically significant effects $(p<0.05)$ from basline to T1 of each group of the variable

impairment of patients' everyday lives and enhance tolerance to medical cancer treatments. As a complementary measure, it could contribute to satisfying therapy goals on physical function (e.g., increasing stamina, reducing restrictions). Further successful reintegration into working life and avoiding certain lifestyle factors, e.g., diet, smoking, alcohol consumption, might be facilitated. Exercise sessions carried out by specialist therapists show substantial advantages over unsupervised physical activities [30-33].

A reduction of 2-3 points in the FACT-B subscales is considered a meaningful change that patients perceive as harmful, leading the clinician to initiate modifications [24, 34]. Care practitioners with different specialties such as a nurse, medical doctor, pathologist, oncologist, radiotherapist, psycho-oncologist, physician assistant, pharmacist, and physical therapist should decide in regular multidisciplinary tumor conferences (MTCs) on cancer patient's management plans. The exchange of best practices for this type of care is multifactorial and requires extra effort in coordination, communication, and cooperation between health care providers [35].

Systematic observing PRO with the FACT-B was feasible in patients with different treatment conditions. Moreover, due to its reliability and time efficiency, identifying patients with decreased quality of life scores within one week after completing cancer therapy turned out to be possible. Thus patients were continuing endocrine therapy persisting adverse events may be expected, which warrants closer examination beyond the time frame chosen in this study to prevent further decline [36]. In this context, late-occurring manifestations associated with radiotherapy, e.g., coronary artery disease, pericarditis, and myocardial dysfunction, have to be considered [37, 38].

Although there is rising awareness of capturing treatment-related QoL of breast cancer patients in scientific studies, monitoring PROs are not yet part of routine oncology practice $[15,16]$. This leads to the assumption that disorders are not consistently recognized. Dismissing patient experiences as an understandable reaction to a life-threatening illness may reduce the success of therapeutic outcomes, which in the worst case negatively affects breast cancer prognosis [39]. Patients who underwent adjuvant chemotherapy experienced significantly unmet sexuality needs, poor physical, functional wellbeing, and more severe breast cancer-specific concerns.
It transpired that details of treatment modalities lead to a more diversified assessment of the patient's perceived situation.

Based on the response behavior, dimensional reductions were detected. A lower PWB at T1 was associated with pain, lack of energy, illness, and being forced to spend time in bed. Some of the poor PWB and BCS incidences may be short-term and were related to all treatments, particularly surgery and radiation therapy. Nonetheless, a significant decrease in BCS is accompanied by an inability to feel like a woman. These results may be related to possible chemotherapy-induced menopausal symptoms, influencing sexual interest and desire $[40,41]$.

Furthermore, the long time of receiving cancer treatment and younger age may increase lifestyle stresses, such as lack of ability to work, child care, or elderly care. Additionally, women felt anxious by changing weight, hair loss, and swollen arms. These findings are attributed to the cancer-specific drug [42] combined with surgical treatment [43]. Studies showed that about $40 \%$ of women with lymph node removal followed by radiation therapy develop secondary lymphedema. Participation in regular physical activity as soon as possible is recommended to stimulate lymphatic circulation, preferably $2-3$ weeks after surgery [44]

In consequence of significantly reduced FWB, patients had a hard time accepting the illness or could not work and enjoy daily activities (e.g., I am enjoying the things I usually do for fun). It is very likely that a fatigue disorder occurred, described by multifactorial symptoms [45]. Supportive forms such as pain therapy [46], nutritional medicine [47], exercise therapy (e.g., yoga) [48] should be implemented in breast cancer patients after completion or during cancer treatment. Especially women receiving chemotherapy reported reduced satisfaction with their sex life, communication about the illness, and experiences of less support from family and friends (SWB). Avoiding discussing the challenges of cancer may become burdensome [49]. Most patients prefer to receive information from a nurse or primary care provider about the impact on intimacy and sexuality shortly after treatment starts [50]. Breast cancer patients receiving active treatment can face many social-emotional challenges and limiting consequences in the HRQoL related to surgical treatment. The increased fear of recurrence, cancer-related distress and body image dissatisfaction are reflected in significantly lower scores. 
A low EWB at $\mathrm{T} 0$ and $\mathrm{T} 1$ was linked to all study groups and may indicate the presence of mental comorbidities. A more substantial alignment with worries about dying and the deterioration of conditions appears necessary, while the attitude of helplessness and hopelessness is progressing. Transparency on mental disorders and identifying patients at risk is all too often lacking [51, 52].

We found reduced PCF prior to cancer treatment in the subgroups using the FACT-Cog to evaluate changes. Differences may be explained by emotional distress associated with the breast cancer diagnosis, causing disrupted functional dynamics $[53,54]$.

Patients receiving chemotherapy experienced an adverse effect on verbal fluency and processing information. Additionally, a majority of people with whom they were interacting told them that they might have trouble thinking clearly or seemed to be confused. The restrictive PCI impacted QoL (e.g., "I have been upset about these problems") and may fuel a vicious cycle of tighter capital, job losses, and the inability to handle instrumental activities of daily living. Concerns about completing education or meeting job requirements to secure financial stability can be debilitating, leading to withdrawal from social life to avoid stigmatization [55]. Women need to receive information about the possible effects of memory loss and advice about coping methods [56].

Underlying mechanisms resulting in lower PCF might be influenced by the state of an inflammatory tumor [57], changes in hormone levels [58], attentional fatigue, and neurotransmitter deregulation [59]. Findings within the chemotherapy-exposed groups may be traced back to neurotoxicity causing neurologic damage [60], cancerrelated cognitive impairment (CRCI) [12, 61], and interhemispheric transfer deficits [62]. However, the origin of CRCI often remains unclear and is not fully understood.

Exercise therapy interventions, individually adapted to the fitness and treatment phase, may counteract the loss of self-confidence and help cope with illness-related symptoms [63]. Frequently exercising of overweight breast cancer survivors showed a positive relationship between BMI and PCI [64].

Nonetheless, the evidence of studies focusing on improving CRCI with exercise treatment is limited [65, 66]. In the light of apparent cognitive deficits, study designs should employ baseline assessments to detect changes accurately. More research is needed to identify how clinical characteristics, including older age, obesity, dietary supplements, stage of cancer, and side effects of chemotherapy, contribute to an increased risk of impairment.

This study adds to the existing literature on patient experiences of cancer care. A clear benefit was that patient-orientated indicators could be assessed quickly and efficiently. By carefully comprehending patients' treatment conditions, prospective capturing of patientperceived circumstances may be improved. The present study results show the importance and the need for differencing between treatments. Studies in larger populations are necessary to guide support based on the medical intervention received.

Knowledge of treatment-specific PRO could serve as a basis for decision-making. The challenge, of course, is to shift from an intuitive approach based on the individual situation to an evidence-based one described by a large number of patients with similar clinical characteristics. This means that every woman with breast cancer could benefit from the generalizable findings of a larger cohort.

Assessing the PCF with the FACT-Cog and the HRQoL with FACT-B should be integrated as a standard measure in women with breast cancer for advanced classifications and standardized definitions of CRCI and health status. Measuring HRQoL and PCF may give multidisciplinary health care professionals guidance for determining the individualized needs of women with breast cancer. The most appropriate supportive care modalities and timing for implementation are required for a beneficial approach in subsequent oncological rehabilitation treatment.

\section{Limitations}

There are limitations to this study as we could not include an additional follow-up analysis. The findings can only be considered preliminary since the number of patients, especially in $S$, was small $(n=13)$. Future investigations are necessary for the generalizability of our results. Treatment groups may not represent all cancer patients, especially not those with severe course of illness. Socioeconomic status, age, BMI, and UICC stage were not investigated as possible modifying factors. A multivariable risk-stratified approach identifying causal inference of reduced FACT-B and FACT-Cog may upgrade the interpretation of data. Measurements in sexuality represent unmet needs and discontent; hence this study's results cannot be compared with those of other studies regarding sexual function.

\section{Conclusion}

In summary, women with breast cancer presented a decreased HRQoL and PCF across all groups, with the most pronounced deterioration in SCR following a multimodal treatment. Significant group-by-time interaction was particularly noticeable in FWB, BCS, PCI, PCA, and Cog QoL. Based on our findings, multidisciplinary support initiated early in breast cancer therapy, especially for women undergoing combined cancer treatment, is needed. Permanent adoption of PRO in oncology practice 
may increase the transparency of patients' perceived circumstances, leading to personalized and optimized acute and survivorship care.

\section{Acknowledgements}

Not applicable.

\section{Authors' contributions}

NPG performed data collection, management, analysis, and manuscript writing. AS helped in data analysis, manuscript editing and provided scientific oversight. MT, JS, and MH helped collect data; BS supplied clinical data and performed data management. PRW and HS provided editorial assistance. All authors have read and approved the final manuscript.

\section{Funding}

Open Access funding enabled and organized by Projekt DEAL. This study was not supported by any funding.

\section{Availability of data and materials}

The datasets used or/and analyzed during the current study are available from the corresponding author on reasonable request.

\section{Declarations}

\section{Ethics approval and consent to participate}

Study approval statement: This study was performed in line with the principles of the Declaration of Helsinki. Approval was granted by the Ethical Review Board of Chemnitz University of Technology (reference number: V-182-17AS-Tumor-20012017). The study is registered with the German Clinical Trials Register (ID: DRKS00014263). Consent to participate: All participants included in this study obtained written informed consent.

\section{Consent for publication}

Not applicable.

\section{Competing interests}

The authors declare that they have no competing interests.

\section{Author details}

${ }^{1}$ Professorship of Sports Medicine/Sports Biology, Institute of Human Movement Science and Health, Faculty of Behavioral and Social Sciences, Chemnitz University of Technology, Thüringer Weg 11, 09126 Chemnitz, Saxony/Sachsen, Germany. ${ }^{2}$ Rotes Kreuz Krankenhaus, Red Cross Hospital, Chemnitz-Rabenstein, Germany. ${ }^{3}$ Clinical Cancer Registry, Tumorzentrum Chemnitz e.V., Chemnitz, Germany. ${ }^{4}$ Department of Sport, Health Sciences and Social Work, Oxford Brookes University, Oxford, UK. ${ }^{5}$ Department of Urology and Urooncology, Vogtland-Klinik, Bad Elster, Germany.

Received: 20 October 2021 Accepted: 9 February 2022

Published online: 21 February 2022

\section{References}

1. Mubarik S, Yu Y, Wang F, Malik SS, Liu X, Fawad M, Shi F, Yu C (2021) Epidemiological and sociodemographic transitions of female breast cancer incidence, death, case fatality and DALYs in 21 world regions and globally, from 1990 to 2017: an age-period-cohort analysis. J Adv Res

2. Ferlay J, Colombet M, Soerjomataram I, Parkin DM, Piñeros M, Znaor A, Bray F (2021) Cancer statistics for the year 2020: an overview. Int J Cancer

3. Barnes B, Kraywinkel K, Nowossadeck E, Schönfeld I, Starker A, Wienecke A, Wolf U (2016) Bericht zum Krebsgeschehen in Deutschland 2016. Robert Koch-Institut. https://doi.org/10.17886/rkipubl-2016-014

4. Katalinic A, Eisemann N, Kraywinkel K, Noftz MR, Hübner J (2020) Breast cancer incidence and mortality before and after implementation of the German mammography screening program. Int J Cancer 147(3):709-718

5. Thorn DR, Hess ARL (2021) Outpatient breast cancer treatment after the hospital: what's next?-Adjuvant medical therapies, management of side effects and common fears, planing and coordination of optimal follow-up care in view of current guidelines. Therapeutische Umschau Revue Therapeutique 78(3):136-144

6. Gold M, Dunn LB, Phoenix B, Paul SM, Hamolsky D, Levine JD, Miaskowski C (2016) Co-occurrence of anxiety and depressive symptoms following breast cancer surgery and its impact on quality of life. Eur J Oncol Nurs 20:97-105

7. Warren LE, Miller CL, Horick N, Skolny MN, Jammallo LS, Sadek BT, Shenouda MN, O'Toole JA, MacDonald SM, Specht MC (2014) The impact of radiation therapy on the risk of lymphedema after treatment for breast cancer: a prospective cohort study. Int J Radiat Oncol Biol Phys 88(3):565-571

8. Kubo Y, Naito T, Mori K, Osawa G, Aruga E (2017) Skeletal muscle loss and prognosis of breast cancer patients. Support Care Cancer 25(7):2221-2227

9. Smit A, Coetzee BJ, Roomaney R, Bradshaw M, Swartz L (2019) Women's stories of living with breast cancer: a systematic review and meta-synthesis of qualitative evidence. Soc Sci Med 222:231-245

10. Hermelink K (2015) Chemotherapy and cognitive function in breast cancer patients: the so-called chemo brain. J Natl Cancer Inst Monogr 2015(51):67-69

11. Janelsins MC, Kohli S, Mohile SG, Usuki K, Ahles TA, Morrow GR. An update on cancer-and chemotherapy-related cognitive dysfunction: current status. In: Seminars in oncology, 2011. vol 3. Elsevier, pp 431-438

12. Ahles TA, Root JC, Ryan EL (2012) Cancer-and cancer treatment-associated cognitive change: an update on the state of the science. J Clin Oncol 30(30):3675

13. Yao C, Bernstein LJ, Rich JB (2017) Executive functioning impairment in women treated with chemotherapy for breast cancer: a systematic review. Breast Cancer Res Treat 166(1):15-28

14. Myers JS. Cancer-and chemotherapy-related cognitive changes: the patient experience. In: Seminars in oncology nursing, 2013. vol 4. Elsevier, pp 300-307

15. van Egdom LS, Oemrawsingh A, Verweij LM, Lingsma HF, Koppert LB, Verhoef C, Klazinga NS, Hazelzet JA (2019) Implementing patient-reported outcome measures in clinical breast cancer care: a systematic review. Value Health 22(10):1197-1226

16. Park J-H, Jung YS, Kim JY, Bae SH (2021) Determinants of quality of life in women immediately following the completion of primary treatment of breast cancer: a cross-sectional study. PLoS ONE 16(10):e0258447

17. Hahn EA, Segawa E, Kaiser K, Cella D, Smith BD (2015) Validation of the Functional Assessment of Cancer Therapy-Breast (FACT-B) quality of life instrument. Am Soc Clin Oncol

18. Brady MJ, Cella DF, Mo F, Bonomi AE, Tulsky DS, Lloyd SR, Deasy S, Cobleigh M, Shiomoto G (1997) Reliability and validity of the Functional Assessment of Cancer Therapy-Breast quality-of-life instrument. J Clin Oncol 15(3):974-986

19. Bitton A, Onega T, Tosteson AN, Haas JS (2014) Toward a better understanding of patient-reported outcomes in clinical practice. Am J Manag Care 20(4):281

20. Mensah J, Graeven U, Wesselmann S (2017) Nationales Zertifizierungsprogramm Krebs Der Onkologe 23(9):711-718

21. Pappot H, Baeksted CW, Nissen A, Knoop A, Mitchell SA, Christensen J, Hjollund NH, Johansen C (2021) Clinical effects of assessing electronic patient-reported outcomes monitoring symptomatic toxicities during breast cancer therapy: a nationwide and population-based study. Breast Cancer. https://doi.org/10.1007/s12282-021-01244-x

22. Maratia S, Cedillo S, Rejas J (2016) Assessing health-related quality of life in patients with breast cancer: a systematic and standardized comparison of available instruments using the EMPRO tool. Qual Life Res 25(10):2467-2480

23. Helou A (2014) Krebsfrüherkennung im Nationalen Krebsplan. Bundesgesundheitsblatt - Gesundheitsforschung - Gesundheitsschutz 57(3):288293. https://doi.org/10.1007/s00103-013-1902-3

24. Webster K, Cella D, Yost K (2003) The Functional Assessment of Chronic Illness Therapy (FACIT) Measurement System: properties, applications, and interpretation. Health Qual Life Outcomes 1(1):1-7

25. Von Ah D, Tallman EF (2015) Perceived cognitive function in breast cancer survivors: evaluating relationships with objective cognitive performance and other symptoms using the functional assessment of cancer therapy-cognitive function instrument. J Pain Symptom Manage 49(4):697-706 
26. Bakeman R (2005) Recommended effect size statistics for repeated measures designs. Behav Res Methods 37(3):379-384

27. Streiner DL (2003) Starting at the beginning: an introduction to coefficient alpha and internal consistency. J Pers Assess 80(1):99-103

28. Beckstein S (2009) Die onkologische Anschlussheilbehandlung in Deutschland-Prinzipien und Strukturen. Notfall \& Hausarztmedizin 35(05):266-270

29. Kreikebohm R, Dankelmann H, Dünn S, Koch F, Kühn M, Schmidt W, Segebrecht B, Zabre B (2008) SGB VI, Sozialgesetzbuch Gesetzliche Rentenversicherung, 3. Aufl, München

30. Juvet L, Thune I, Elvsaas IØ, Fors E, Lundgren S, Bertheussen G, Leivseth G, Oldervoll L (2017) The effect of exercise on fatigue and physical functioning in breast cancer patients during and after treatment and at 6 months follow-up: a meta-analysis. The Breast 33:166-177

31. Stout NL, Baima J, Swisher AK, Winters-Stone KM, Welsh J (2017) A systematic review of exercise systematic reviews in the cancer literature (2005-2017). PM\&R 9(9):S347-S384

32. Spei M-E, Samoli E, Bravi F, La Vecchia C, Bamia C, Benetou V (2019) Physical activity in breast cancer survivors: a systematic review and metaanalysis on overall and breast cancer survival. The Breast 44:144-152

33. Hashemi SHB, Karimi S, Mahboobi H (2014) Lifestyle changes for prevention of breast cancer. Electron Physician 6(3):894

34. Eton DT, Cella D, Yost KJ, Yount SE, Peterman AH, Neuberg DS, Sledge GW, Wood WC (2004) A combination of distribution-and anchor-based approaches determined minimally important differences (MIDs) for four endpoints in a breast cancer scale. J Clin Epidemiol 57(9):898-910

35. Prades J, Remue E, Van Hoof E, Borras JM (2015) Is it worth reorganising cancer services on the basis of multidisciplinary teams (MDTs)? A systematic review of the objectives and organisation of MDTs and their impact on patient outcomes. Health Policy 119(4):464-474

36. Garreau JR, DeLaMelena T, Walts D, Karamlou K, Johnson N (2006) Side effects of aromatase inhibitors versus tamoxifen: the patients' perspective. Am J Surg 192(4):496-498

37. Łapińska G, Kozłowicz-Gudzińska I, Sackiewicz-Słaby A (2012) Equilibrium radionuclide ventriculography in the assessment of cardiotoxicity of chemotherapy and chemoradiotherapy in patients with breast cancer. Nucl Med Rev 15(1):26-30

38. Chuy KL, Nahhas O, Dominic P, Lopez C, Tonorezos E, Sidlow R, Straus D, Gupta D (2019) Cardiovascular complications associated with mediastinal radiation. Curr Treat Options Cardiovasc Med 21(7):1-20

39. Sitlinger A, Zafar SY (2018) Health-related quality of life: the impact on morbidity and mortality. Surg Oncol Clin N Am 27(4):675

40. Biglia N, Moggio G, Peano E, Sgandurra P, Ponzone R, Nappi RE, Sismondi P (2010) Effects of surgical and adjuvant therapies for breast cancer on sexuality, cognitive functions, and body weight. J Sex Med 7(5):1891-1900

41. Hwang SY, Chang SJ, Park B-W (2013) Does chemotherapy really affect the quality of life of women with breast cancer? J Breast Cancer 16(2):229-235

42. Choi S-M, Lee S-H, Yang Y-S, Kim B-C, Kim M-K, Cho K-H (2001) 5-Fluorouracil-Induced leukoencephalopathy breast cancer. J Korean Med Sci 16:328-334

43. Cormier JN, Askew RL, Mungovan KS, Xing Y, Ross MI, Armer JM (2010) Lymphedema beyond breast cancer: a systematic review and meta-analysis of cancer-related secondary lymphedema. Cancer 116(22):5138-5149

44. Johansson K, Karlsson K, Nikolaidis P (2015) Evidence-based or traditional treatment of cancer-related lymphedema. Lymphology 48(1):24-27

45. Dhruva A, Dodd M, Paul SM, Cooper BA, Lee K, West C, Aouizerat BE, Swift PS, Wara W, Miaskowski C (2010) Trajectories of fatigue in patients with breast cancer before, during, and after radiation therapy. Cancer Nurs 33(3):201

46. Abrahams H, Gielissen M, Verhagen C, Knoop H (2018) The relationship of fatigue in breast cancer survivors with quality of life and factors to address in psychological interventions: a systematic review. Clin Psychol Rev 63:1-11

47. Pereira PTVT, Reis AD, Diniz RR, Lima FA, Leite RD, da Silva MCP, Guerra RNM, de Moraes Vieira ÉB, Garcia JBS (2018) Dietary supplements and fatigue in patients with breast cancer: a systematic review. Breast Cancer Res Treat 171(3):515-526
48. Dong B, Xie C, Jing X, Lin L, Tian L (2019) Yoga has a solid effect on cancer-related fatigue in patients with breast cancer: a meta-analysis. Breast Cancer Res Treat 177(1):5-16

49. Pennebaker JW, Chung CK. Expressive writing, emotional upheavals, and health (2007)

50. Den Ouden ME, Pelgrum-Keurhorst MN, Uitdehaag MJ, De Vocht HM (2019) Intimacy and sexuality in women with breast cancer: professional guidance needed. Breast Cancer 26(3):326-332

51. Watson M, Homewood J, Haviland J, Bliss JM (2005) Influence of psychological response on breast cancer survival: 10-year follow-up of a population-based cohort. Eur J Cancer 41(12):1710-1714

52. Harris LN, Stanton AL (2020) Cancer and psycho-oncology. The Wiley Encyclopedia of Health Psychology, pp 73-81

53. Tang L, Fritzsche K, Leonhart R, Pang Y, Li J, Song L, Fischer I, Koch M, Wuensch A, Mewes R (2017) Emotional distress and dysfunctional illness perception are associated with low mental and physical quality of life in Chinese breast cancer patients. Health Qual Life Outcomes 15(1):1-10

54. Kesler SR, Adams M, Packer M, Rao V, Henneghan AM, Blayney DW, Palesh O (2017) Disrupted brain network functional dynamics and hyper-correlation of structural and functional connectome topology in patients with breast cancer prior to treatment. Brain Behav 7(3):e00643

55. Ernst J, Mehnert A, Dietz A, Hornemann B, Esser P (2017) Perceived stigmatization and its impact on quality of life-results from a large registerbased study including breast, colon, prostate and lung cancer patients. BMC Cancer 17(1):741

56. Munir F, Kalawsky K, Lawrence C, Yarker J, Haslam C, Ahmed S (2011) Cognitive intervention for breast cancer patients undergoing adjuvant chemotherapy: a needs analysis. Cancer Nurs 34(5):385-392

57. van der Willik KD, Koppelmans V, Hauptmann M, Compter A, Ikram MA, Schagen SB (2018) Inflammation markers and cognitive performance in breast cancer survivors 20 years after completion of chemotherapy: a cohort study. Breast Cancer Res 20(1):1-10

58. Underwood E, Rochon P, Moineddin R, Lee P, Wu W, Pritchard K, Tierney $M$ (2018) Cognitive sequelae of endocrine therapy in women treated for breast cancer: a meta-analysis. Breast Cancer Res Treat 168(2):299-310

59. Eshragh J, Dhruva A, Paul SM, Cooper BA, Mastick J, Hamolsky D, Levine JD, Miaskowski C, Kober KM (2017) Associations between neurotransmitter genes and fatigue and energy levels in women after breast cancer surgery. J Pain Symptom Manag 53(1):67-84.e67

60. Sałat K (2020) Chemotherapy-induced peripheral neuropathy—part 2: focus on the prevention of oxaliplatin-induced neurotoxicity. Pharmacol Rep 72(3):508-527

61. Ono M, Ogilvie JM, Wilson JS, Green HJ, Chambers SK, Ownsworth T, Shum DH (2015) A meta-analysis of cognitive impairment and decline associated with adjuvant chemotherapy in women with breast cancer. Front Oncol 5:59

62. Tao L, Wang L, Chen X, Liu F, Ruan F, Zhang J, Shen L, Yu Y (2020) Modulation of interhemispheric functional coordination in breast cancer patients receiving chemotherapy. Front Psychol 11:1689

63. Lan M, Zhang L, Zhang Y, Yan J (2019) The relationship among illness perception, coping and functional exercise adherence in Chinese breast cancer survivors. J Adv Nurs 75(1):75-84

64. Myers JS, Wick JA, Klemp J (2015) Potential factors associated with perceived cognitive impairment in breast cancer survivors. Support Care Cancer 23(11):3219-3228

65. Majithia N, Temkin SM, Ruddy KJ, Beutler AS, Hershman DL, Loprinzi CL (2016) National Cancer Institute-supported chemotherapy-induced peripheral neuropathy trials: outcomes and lessons. Support Care Cancer 24(3):1439-1447

66. Cai H, Li G, Hua S, Liu Y, Chen L (2017) Effect of exercise on cognitive function in chronic disease patients: a meta-analysis and systematic review of randomized controlled trials. Clin Interv Aging 12:773

\section{Publisher's Note}

Springer Nature remains neutral with regard to jurisdictional claims in published maps and institutional affiliations. 